\title{
Pragmatic Approch for Financial Networking System Using Cyber Physical Systems Through Advanced DataMining Concepts
}

\author{
Mrs. Sharada Mangipudi ${ }^{1}$, Dr. P. Suresh Verma ${ }^{2}$, Dr. M. Srinivasa Rao ${ }^{3}$ \\ ${ }^{\text {I}}$ (Professor\& HOD, Dept. of CSE\&IT, St. Peters Engineering College, Hyderabad, AP, India, \\ ${ }_{2}^{2}$ (Professor, Dept. of CSE, Nannaya University, Rajamundry, AP, India, \\ ${ }^{3}$ (Professor, Dept. of CSE, JNTU, Hyderabad, Hyderabad, AP, India,
}

\begin{abstract}
Last few decades witnessed the proliferation of financial reforms, liberalization and globalization of economy coupled with rapid revolution in information technology (IT).The paper presents the benefits of applying data mining $(D M)$ and data warehousing $(D W)$ techniques in customer relationship management (CRM) of the financial Networking.Detecting and preventing fraud is difficult, because fraudsters develop new schemes all the time, and the schemes grow more and more sophisticated to elude easy detection. So the Proposed cyber-physical systems (CPS) provide a novel security challenges due to their heterogeneity and complexity. In this present paper the basic ideology is to apply $(D M)$ And $(D W)$ techniques and also to monitor the entire Financial Network System (FNS) through CPS to alert the user and entire network about the intruder flow in the network.
\end{abstract}

Keywords: Data warehousing, Data Mining, Cyber Physical Systems, Financial Network System.

\section{INTRODUCTION}

As we are in the era of modern technology where the science and technology is growing like the blooming forest and with the response to this growth the enemy at the another end is ready to destroy and corrupt the technological growth with much more intensity. The intention of this paper is to provide security to the user to become happy customer and also to break the attempt made by the intruders to tap into the network. The below figure illustrates the overall architecture of the Financial Network System[12] (FNS) in which to the FNS six block modes are connected(User, Business Intelligence, Security, Management Information Systems, Data mining [3, 9], Cyber Physical Systems. Where it sends and receives the information in both the directions.

Data Mining

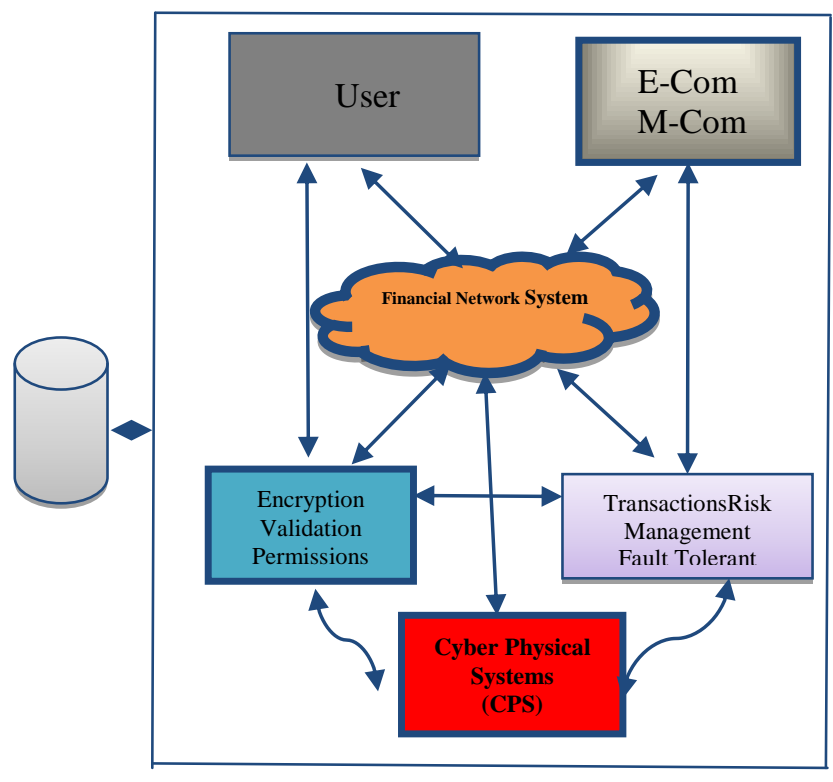

Fig. 1.1 Financial Network System Architecture

$$
\bigcup_{i=1}^{n} F N S_{(B I, M I S, S, C P S, D B)} X(x i)
$$


The above equation represents that the user can utilize the services under Financial Network Systems that connects to (BI, MIS, S, CPS, DB)

U- User,BI- Business Intelligence, S- Security, D.B- Data mining, MIS- Management Information System, CPS- Cyber Physical Systems,FNS- Financial Network System

User: User is a customer related to bank who can access the operation through FNS.

Business Intelligence: B.I is a roof that refers to a wide variety of software applications to access the data with an banking sector.

Example: E- commerce applications, banking applications.

Security: The term security gives the assurance to the user and also to the organization from potential attackers. In Financial Network System the security concentrates in encrypting the data through RSA algorithm and validating the user to check his authentication and to give permission to the valid user or genuine user only.

Management Information System: Management information system provides the information to the FNS through Cyber Physical systems to manage the transactions in the FNS and also it manage the risk and fault through the security audit and monitoring at the CPS level.

Data mining: Data base is the representation of the data in the organized form taken through different sources in the FNS.

Cyber Physical Systems: The term Cyber Physical system ${ }^{[2]}$ is the collaboration between Physical Systems and Computational elements. The CPS in the entitled paper is the king of the entire Financial Network System where CPS will have the connection or link to all the nodes that are participating in the FNS. The main responsibility of the CPS is monitoring entire network, validating the requests between each node and alerting the MIS and FNS. If it suspects any unauthorized entry, CPS conducts Security Audit to fix up the holes in the FNS.

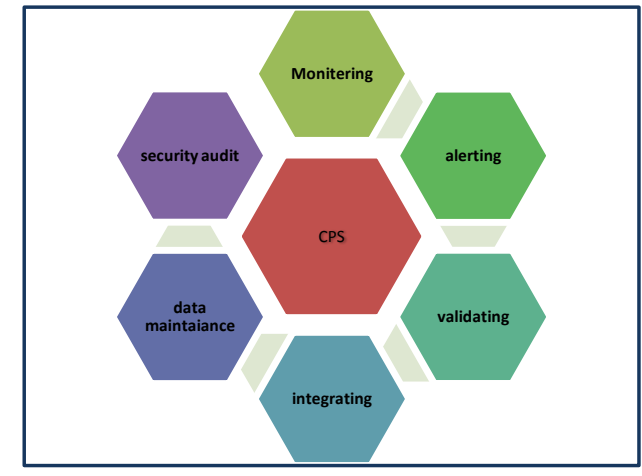

Fig.1.2 CPS Functions in Financial Network Systems

The figure 1.3 below illustrates the overall architecture of the FNS where all the nodes are monitored by Cyber Physical Systems. Here when the client feeds the data into the node the user information is validated by the security nodeand only after this the user can access a wide variety of the software applications under business intelligence. Now the main task for the network like FNS is not only to give processed response to the user but it should also have the ability to oppose the potential attack from the intruder. Many security applications in today's technological era can 


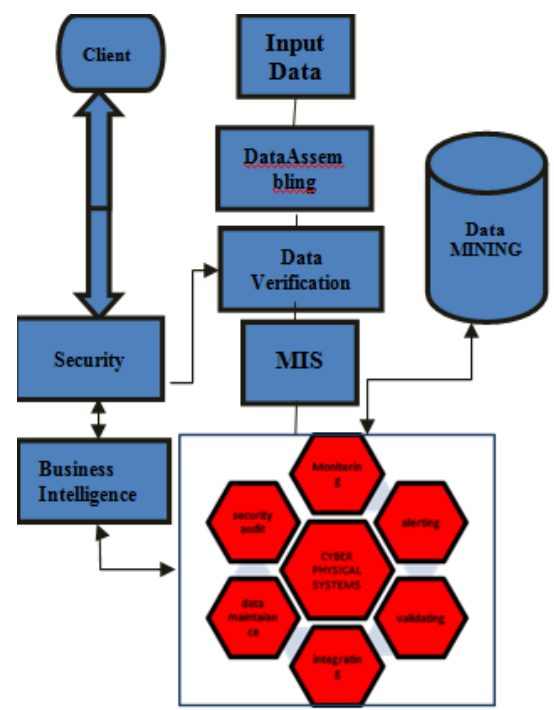

Fig 1.3 Architecture view of monitoring System through CPS

do this job. But the problem in this security application is, it can't defend the new approach of the attacker and therefore the result is loss of valuable data.So in today's technological era every organization should need a security watch application in such a way that it should oppose all the possible ways of attacks and also it should not alert the entire network about the attack. So to do this dynamic task we need CYBER PHYSICAL SYSTEM which performs the monitoring, alerting, validating and security audit for the network. CPS main functionality is to monitor the behaviour of the user and nodes attached to the Financial Network System and then controlling the FNS through Management Information Systems.

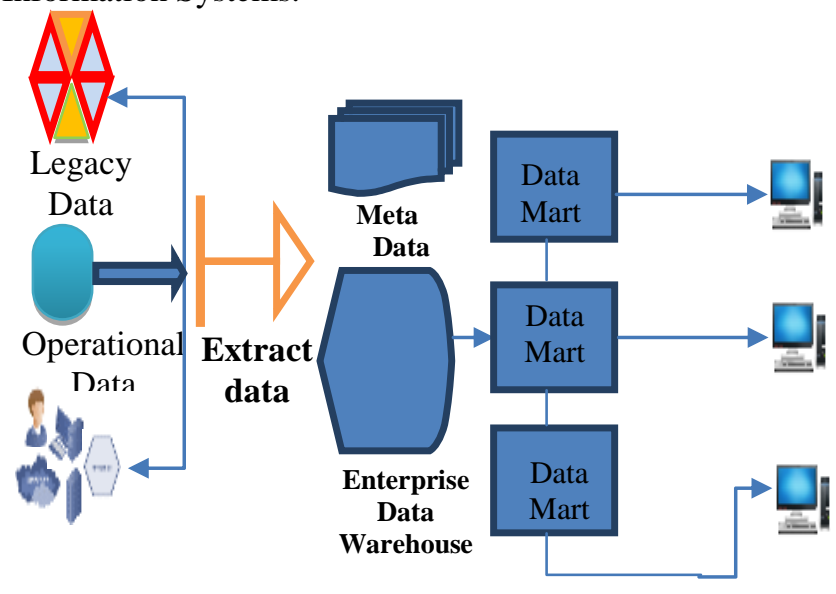

Fig 1.4 Architecture view of Data Mining and Data Warehousing in FNS.

The above figure shows the data mining and data warehousing technique in Financial Network systems. Banks require a variety of solutions ranging from a fully centralized global data warehouse (DW), legacy data ${ }^{[11]}$ to non integrated datamarts (DM) for the emerging needs of the departments. Both of these extreme solutions have significant disadvantages along with their benefits, so it is worth considering the indirect variant presented here based on a global data source ODS (Operational Data Store), a global DW and DMs. ODS collects data from various systems, cleaning and restructuring the data before loading it into the warehouse. Data structures and rules of purification and transformation are contained in the metadata repository. Info services DM is designed to provide an "early warning" by monitoring critical areas through Cyber Physical Systems.

\section{ANALYSIS}

\section{A. Data Mining Applications}

Data Mining is widely used in diverse areas. There are number of commercial data mining system available today yet there are many challenges in this field. In this tutorial we will applications and trend of Data Mining.

I. Financial Data Analysis

II. Retail Industry

III. Telecommunication Industry 
IV. Biological Data Analysis

V. Other Scientific Applications

Financial Data Analysis

The financial data in banking and financial industry is generally reliable and of high quality which facilitates the systematic data analysis and data mining

\section{Retail Industry}

Data Mining has its great application in Retail Industry because it collects large amount data from on sales, customer purchasing history, goods transportation, consumption and services. It is natural that the quantity of data collected will continue to expand rapidly because of increasing ease, availability and popularity of web. The Data Mining in Retail Industry helps in identifying customer buying patterns and trends. That leads to improved quality of customer service and good customer retention and satisfaction.

\section{Telecommunication Industry}

Today the Telecommunication industry is one of the most emerging industries providing various services such as fax, pager, cellular phone, Internet messenger, images, e-mail, web data transmission etc. Due to the development of new computer and communication technologies, the telecommunication industry is rapidly expanding. This is the reason why data mining is become very important to help and understand the business. Data Mining in Telecommunication industry helps in identifying the telecommunication patterns, catch fraudulent activities, make better use of resource, and improve quality of service. Here is the list examples for which data mining improve telecommunication services

\section{Biological Data Analysis}

Now a days we see that there is vast growth in field of biology such as genomics, proteomics, functional Genomics and biomedical research. Biological data mining is very important part of Bioinformatics. Following are the aspects in which Data mining contribute for biological data analysis:

\section{IMPLEMENTATION}

In this paper we focus on the security to the users of FNS and data mining. The CPS activates all the user details in and around the network.

The flow of action of user as follows.

1. User will try to login

2. Server verifies authentication success then continues available services otherwise registers those as new users

3. Utilizes available services \& complete the process.

4. Generate report.

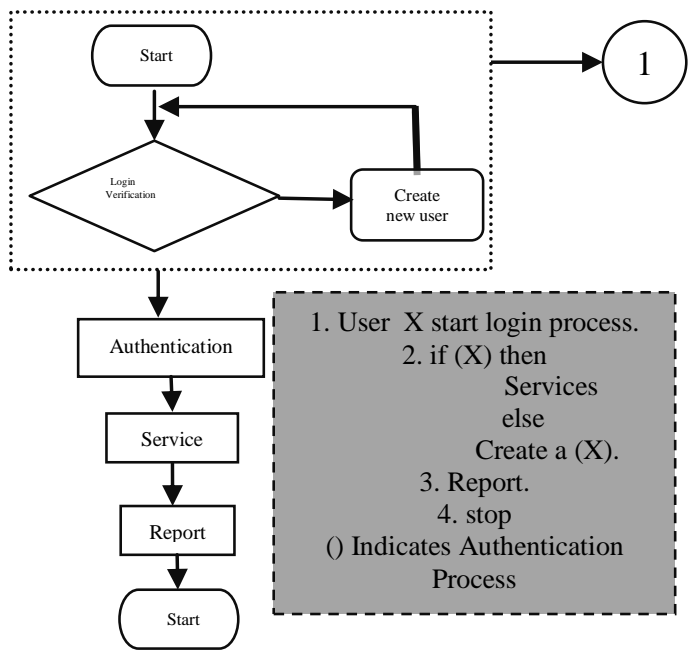

Fig. 3.1 User service activities

Authentication function of $\mathrm{X}$ is $\mathrm{F}_{\mathrm{X}}\left(\mathrm{X}_{\mathrm{i}}\right)$

Where X-user

( ):- Authentication

$\mathrm{F}_{\mathrm{X}}\left(\mathrm{x}_{\mathrm{i}}\right)$ :- is Function type of Service 
$\mathrm{x}_{\mathrm{i}}$ - Particular Service of $\mathrm{i}$

$\mathrm{S}_{\mathrm{X}}\left(\mathrm{x}_{\mathrm{i}}\right)$ :- Service type of Authorized

$\mathrm{X}$ With type $\mathrm{X}_{\mathrm{i}}$ all authorized users $=\sum_{k=1}^{n} \mathrm{AU}_{\mathrm{X}}\left(\mathrm{x}_{\mathrm{k}}\right)$

Report all users [A]: $\bigcup_{i=1}^{n} X\left[x_{i}\right]$

Only services $S=[A]-X$

The above Fig.3.1 indicates the user $\mathrm{X}$ with authentication process $(\mathrm{X})$ and available services to authorized users are $\mathrm{S}_{\mathrm{X}}\left(\mathrm{x}_{\mathrm{i}}\right)$. All the reports of the available users are $[\mathrm{A}]: \mathrm{U}_{i=1}^{n} X\left[x_{i}\right]$

\subsection{Verification and Transaction}
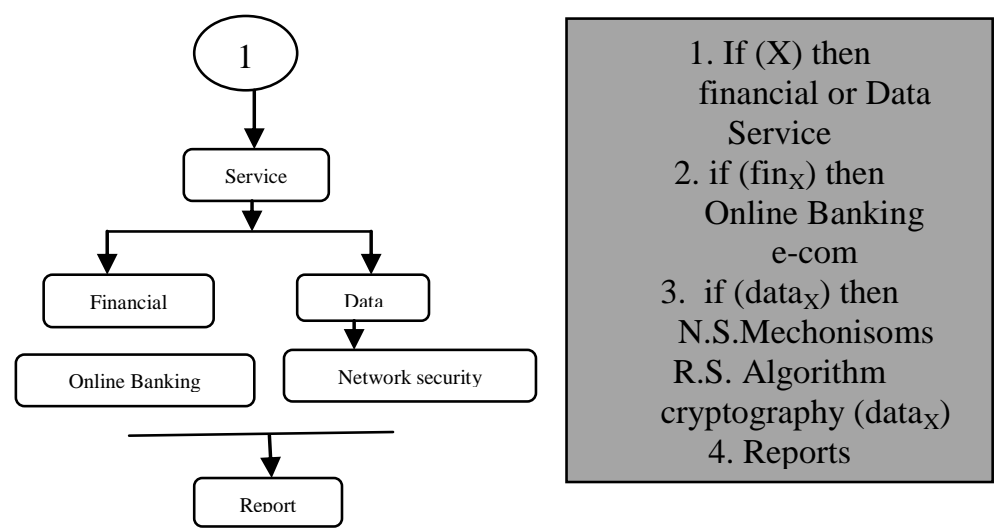

Fig. 3.1.1 Verification and validation of Financial and data services authentication function of $\mathrm{X}$ is $\mathrm{F}_{\mathrm{X}}\left(\mathrm{x}_{\mathrm{i}}\right)$ where X- user

() -: Authentication

$\operatorname{Fin}_{X}\left(x_{i}\right)-$ : is Financial Authentication of $X$

$\operatorname{Data}_{X}\left(x_{i}\right)-$ : is Financial Authentication of $X$ $\mathrm{x}_{\mathrm{i}}$ - Particular Service of

$\mathrm{S}_{\mathrm{X}}\left(\mathrm{x}_{\mathrm{i}}\right)$-: Service type of Authorized $\mathrm{X}$ With type $\mathrm{X}_{\mathrm{i}}$ all authorized users $=\sum_{i=1}^{n} \mathrm{AU}_{\mathrm{X}}\left(\mathrm{x}_{\mathrm{i}}\right)$,

Report all Transactions [B]: $\bigcup_{i=1}^{n}$ Fin $_{X}\left[x_{i}\right] \mathrm{U}_{i=1}^{n}$ Data $_{X}\left[x_{i}\right]$

The above fig.3.1.1 provides financial and data transactions by using online banking services with network security by using RSA algorithm.

\subsection{Storage \& Retrieval of Data}

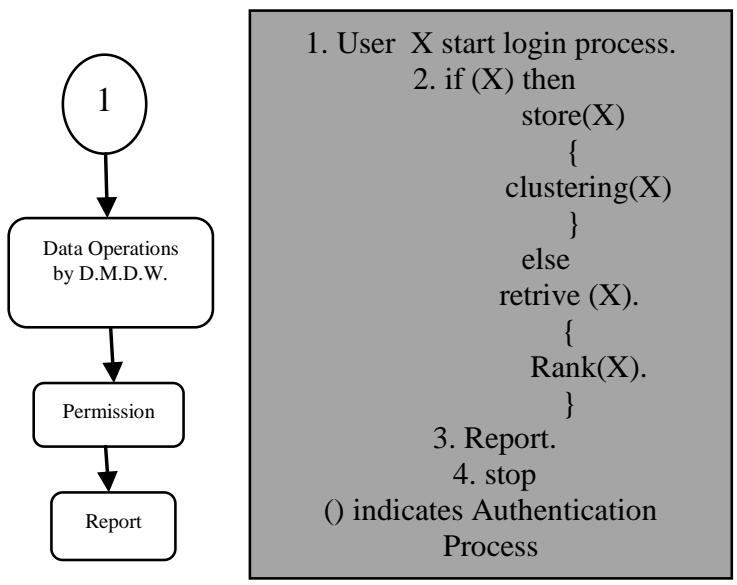

Fig.3.2.1 Storage and retrieval data using DMDW techniques.

The above fig.3.2.1 show the data operations on data storage by using clustering and data retrieval by using ranking or divide and conquer mechanism of data storing, searching mechanisms in data mining as well as data warehousing. 
1. User X start login process.

2. if $(X)$ then

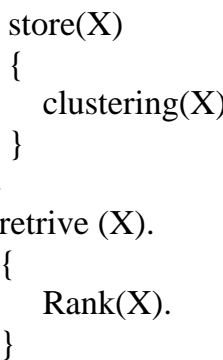

3. Report.

4. stop

() indicates Authentication Process

\subsection{CPS Monitoring}

CPS: Algorithm

Switch (X):

Case A: Authentication

Switch $\left(\mathrm{N}_{\mathrm{x}}\right.$ :

Case F: Calculating Financial Transactions

Break

Case N: Calculating the Network Transactions

Break

Switch (D)

Case $\mathrm{S}_{\mathrm{t}}$ : Storage operations

Break

Case $\mathrm{A}_{\mathrm{c} \text { : }}$ Accessing operations

Break

Case $\mathrm{R}_{\mathrm{t}}$ : Retrieval operations

End(3)

Equitation

\section{ANALYSIS}

$-\quad$ indicates Tolerance

$\left\ulcorner_{U}\right.$ - indicates Tolerance of Users

$r_{\mathrm{N}}$ - indicates Tolerance of Networking

$r_{D}$ - indicates Tolerance of DMDW

$\ulcorner$ CPS - indicates Tolerance of CPS

$$
\begin{gathered}
\sum_{k=1}^{n} \mathrm{U}\left(\mathrm{X}_{\mathrm{k}}\right) \\
\left\ulcorner_{\mathrm{U}}=\right. \\
\sum_{k=1}^{n}\left(\mathrm{X}_{\mathrm{k}}\right)
\end{gathered}
$$

The tolerance of the User should be calculated by the total number of performed operations in the network with respect to total number of users in the network is $\sum_{k=1}^{n} \mathrm{U}\left(\mathrm{X}_{\mathrm{k}}\right)$. Assume that the total number of operations in the FNS is $\sum_{k=1}^{n}\left(\mathrm{X}_{\mathrm{k}}\right)$

$$
\begin{gathered}
\left\ulcorner_{\mathrm{N}}=\sum_{k=1}^{n}\left\{\operatorname{fin}\left(\mathrm{X}_{\mathrm{k}}\right)+\operatorname{nw}\left(\mathrm{X}_{\mathrm{k}}\right)\right\}\right. \\
\sum_{k=1}^{n}\left\{\mathrm{fin}+\mathrm{nw}_{\mathrm{k}}\right\}
\end{gathered}
$$




$$
\begin{gathered}
\left\ulcorner_{\mathrm{D}}=\sum_{k=1}^{n}\left\{\operatorname{st}\left(\mathrm{X}_{\mathrm{k}}\right)+\operatorname{Acc}\left(\mathrm{X}_{\mathrm{k}}\right)+\operatorname{Re}\left(\mathrm{X}_{\mathrm{k}}\right)\right\}\right. \\
\sum_{k=1}^{n}\left\{\mathrm{st}+\mathrm{Acc}_{\mathrm{k}}+\operatorname{Re}_{\mathrm{k}}\right\}
\end{gathered}
$$

Similarly the tolerance of Network and DMDW will be calculated in the above tolerance of user

$\left\ulcorner_{\mathrm{CPS}}=\left\{\left\ulcorner_{\mathrm{U}}+\left\ulcorner_{\mathrm{N}}+\left\ulcorner_{\mathrm{D}}\right\} / 3\right.\right.\right.\right.$

Finally the average of tolerance of the network, User and DMDW will be tolerance of CPS ( $\left(r_{\mathrm{CPS}}\right)$

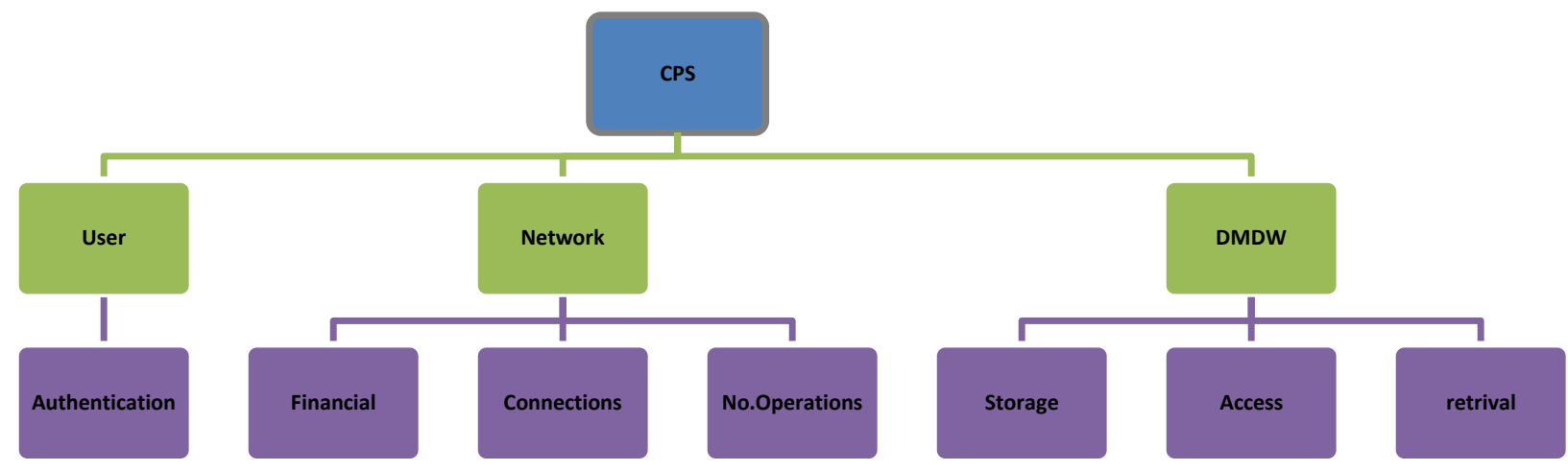

Estimated Output

User - security level

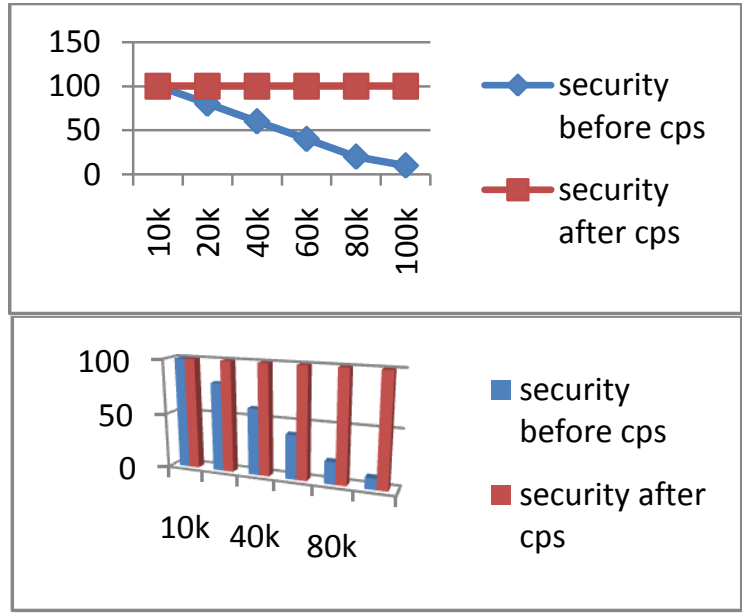

The user and security graph will vary before and after CPS system. After CPS the tolerance is appoximately zero.

Transactions - Security Level

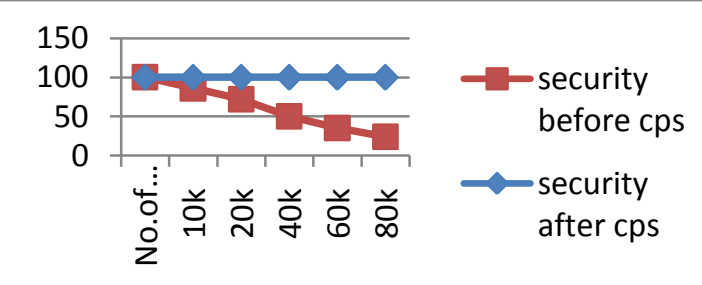




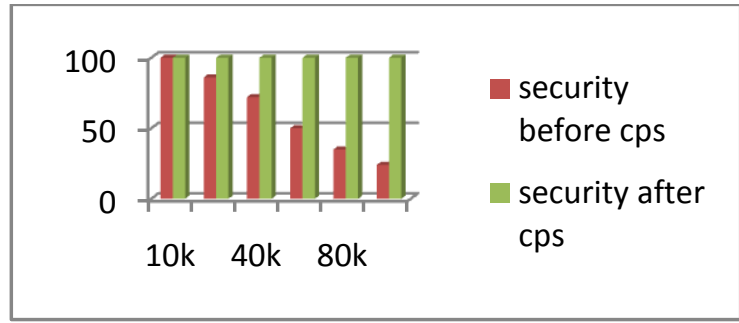

The above charts indicate the transaction- security level which varies before and after CPS. The tolerance of Transcation Security is appoximately zero at CPS.

Data mining - networking system

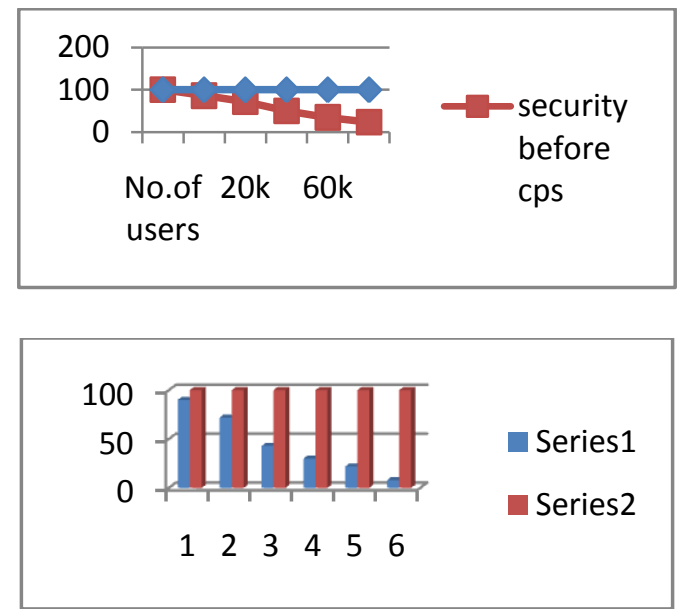

The above charts indicates the Data with respect to mining and network level which varies before and after CPS. The tolerance of Data with respect to mining and network level is approximately zero at CPS.

\section{CONCLUSION AND FURTHER SCOPE}

The main approach of this research paper is, the combination of CPS with advanced Data Mining techniques provide a high level security to the users and user operations inside and outside the financial networking system. It also monitors the connection status in the network, user level status, traffic analysis, risk assessment, cluster mechanisms in data mining. Further, the CPS alone provides a high level security to the user and information in cluster with multiple key length.

\section{REFERENCES}

[1]. Mrs. Sharada Mangipudi , J. Vijay Gopal ,Dr. P. Suresh Verma , Dr. M.Srinivasa Rao Developing Multi Level Security System Using Esp Te-hnique By An Advanced Data Mining Concepts

[2]. Lee, E.A. EECS , Center for Hybrid \& Embedded Software Syst., Univ. of California at Berkeley, Berkeley, CA Cyber Physical Systems: Design Challenges

[3]. Neelamadhab Padhy1, Dr. Pragnyaban Mishra 2, and Rasmita Panigrahi3, The Survey of Data Mining Applications And Feature Scope (IJCSEIT),Vol.2, No.3, June 2012.

[4]. Surajit Chaudhuri Umeshwar Dayal, An Overview of Data Warehousing and OLAP Technology, Appears in ACM Sigmod Record, March 1997.

[5] .Inmon, W.H., Building the Data Warehouse. John Wiley, 1992.

[6]. http://www.olapcouncil.org

[7]. Codd, E.F., S.B. Codd, C.T. Salley, "Providing OLAP (On-Line Analytical Processing) to User Analyst: An IT Mandate." Available from Arbor Software's web site http://www.arborsoft.com/OLAP.html.

[8]. http://pwp.starnetinc.com/larryg/articles.html

[9]. Kimball, R. The Data Warehouse Toolkit. John Wiley, 1996. Barclay, T., R. Barnes, J. Gray, P. Sundaresan, "Loading Databases using Dataflow Parallelism." SIGMOD Record, Vol. 23, No. 4, Dec.1994.

[10]. Mapping the company's Legacy Data Model to SDTM, Nicolas Dupuis, Anja Feuerbacher, Bruce Rogers, F. Hoffmann-La Roche, Basel, Switzerland, PhUSE 2012.

[11]. Data.dcs: Converting Legacy Data into Linked Data, Matthew Rowe, OAK Group, Department of Computer Science, University of Sheffield, Regent Court, 211 Portobello Street S1 4DP Sheffield, United Kingdom.

[12]. Systemic Risk and Stability in Financial Networks, Daron Acemoglu† Asuman Ozdaglarł Alireza Tahbaz-Salehi.

[13]. A Network Model Approach to Systemic Risk in the Financial System, January 2013, Han Chen and Shaun Wang1

[14]. Financial Networks Key to Understanding Systemic Risk By Camelia Minoiu and Sanjay Sharma, May 28, 2014. 
[15]. Castren, O. and Kavonius, I. K. "Balance Sheet Interlinkages and Macro-financial Risk Analysis in the Euro Area." European Central Bank Working Paper Series 1124, December 2009.

[16] .http://business-fundas.com/2011/e-commerce-and-e-business-models/

[17]. https://www.iconfinder.com/icons/270036/analysis_analytics_chart_charts_diagram_earnings_ecommerce

[18]. http://business-fundas.com/2011/e-commerce-and-e-business-models/

\section{Bibliography}

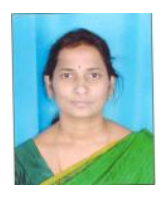

M Sarada Varalakshmi obtained her B.Tech (CSE) from Mysore University, M.Tech (S.E.) from JNTU Hyderabad in the year 2009 and pursuing Ph.D from JNTU Hyderabad, having more than 10 years of Teaching experience working as a Associate professor \& Head of Department of computer science and engineering \& Information Technology in ST.Peters Engineering College, Maisammaguda, Hyderabad, AP-India, she is specialized in Computer Networks, Adaptive security Key generation methods, Data Mining \& Ware house concepts, Social security and security attack control techniques, Multi level and Multi lateral systems design concepts with wider experience,. Presented 3 international and 5 national publications and atteneded more than 10 international and national workshops and conferences.

Email: sharada.mangipudi07@gmail.com 